\title{
Measurement of pain in children
}

\author{
Patrick J McGrath OC PhD FRSC, Margot Latimer PhD, \\ G Allen Finley MD FRCPC FAAP, Christine T Chambers PhD, Guest Editors
}

$\mathrm{P}$

ain research in infants, children and youth has come a long way since the 1970s and 1980s, when it was seriously debated whether children, especially young children, really experienced pain. Now, there is virtually universal agreement that infants and children experience pain. Just over a decade ago, we edited a book on pain measurement in children (1). This special issue of Pain Research $\mathbb{E}$ Management is a reprise of this topic.

This collection of papers focuses on the latest developments in pain assessment and measurement. The authors are all leading contributors on their topics and they present the latest thinking in their area. Pain is still measured by self-report, behaviour and physiology, but there are new and more sophisticated ways of obtaining behavioural and self-report measures. There has not been enough new work on physiological strategies of measuring pain to warrant a review. We believe that the development of various brain measures of pain will be an exciting area in the future.

These papers are derived from the keynote addresses given October 2 to 5, 2008, at the 7th Biennial International Forum on Pediatric Pain, held at White Point Beach Resort, Nova Scotia. The authors have used the best scientific evidence to challenge our thinking about pain measurement in children, and we hope that Pain Research $\mathcal{E}$ Management readers find these papers interesting, helpful and provocative.

\section{REFERENCE}

1. Finley GA, McGrath PJ, eds. Measurement of Pain in Infants and Children. Seattle: IASP Press, 1998. 


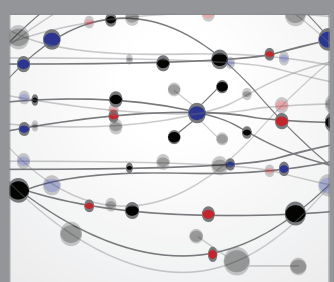

The Scientific World Journal
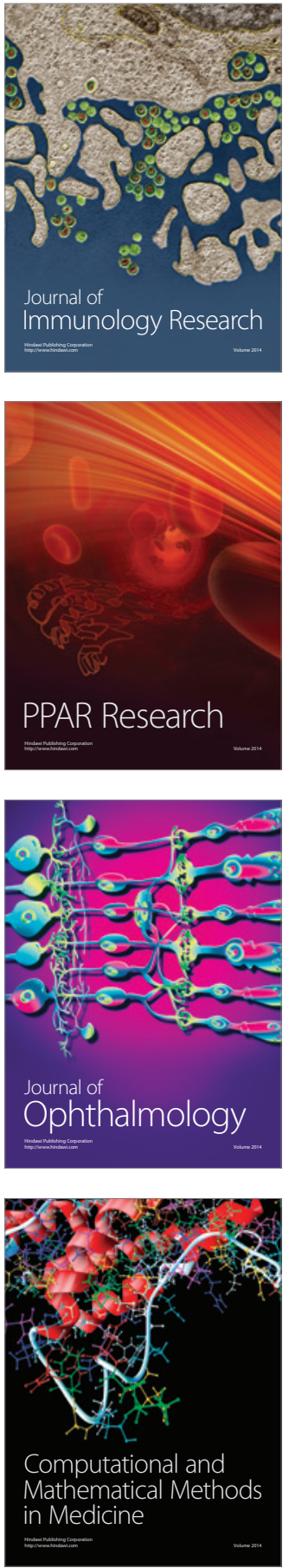

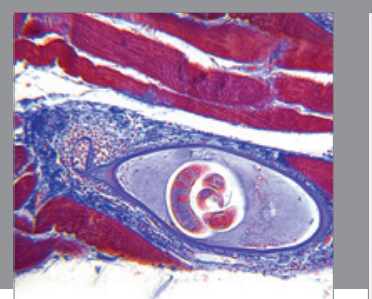

Gastroenterology Research and Practice

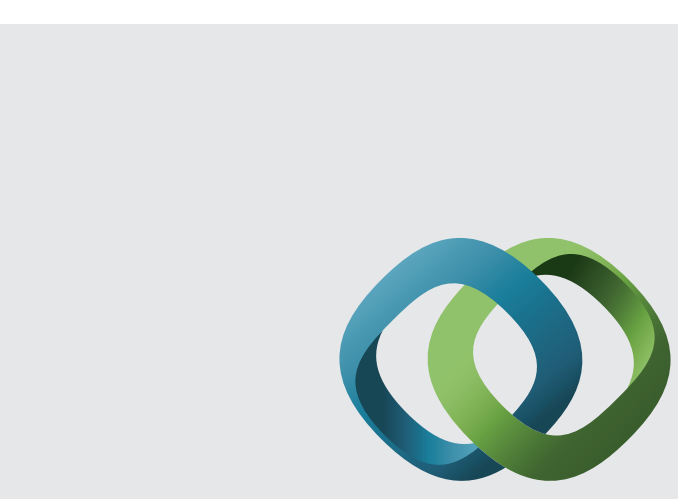

\section{Hindawi}

Submit your manuscripts at

http://www.hindawi.com
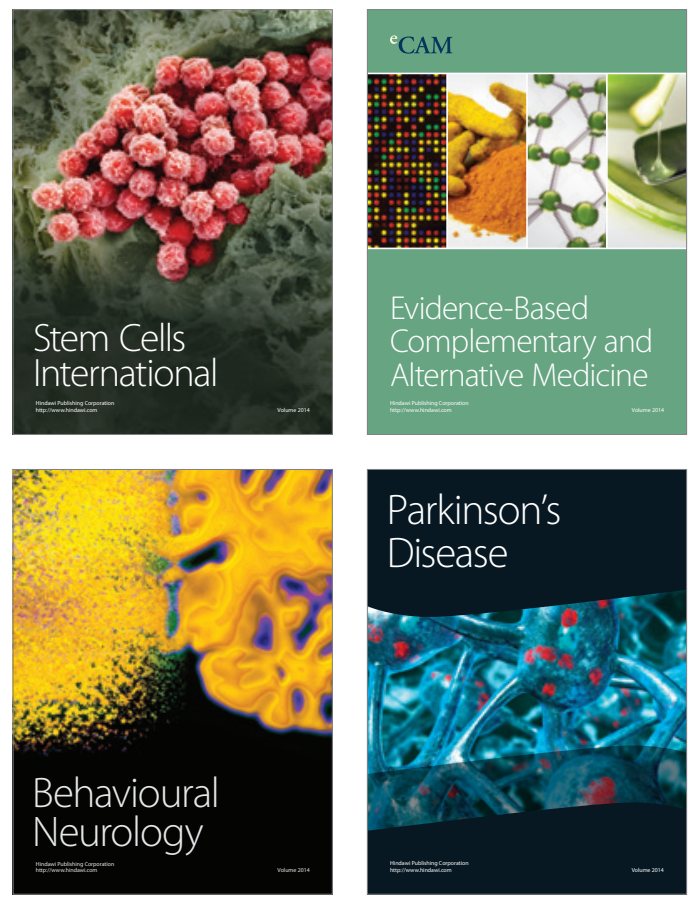
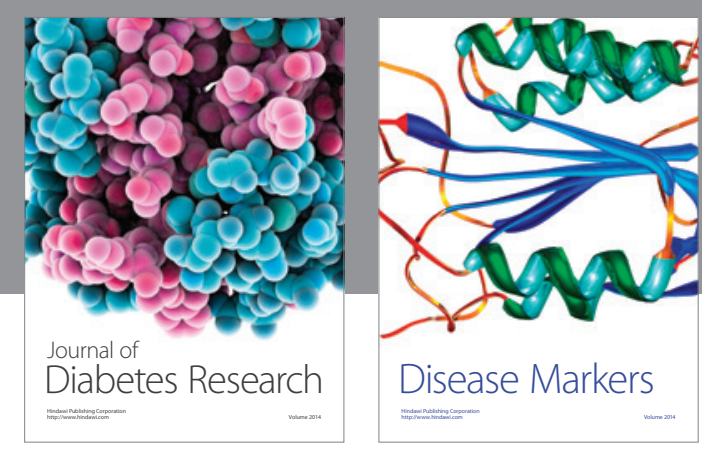

Disease Markers
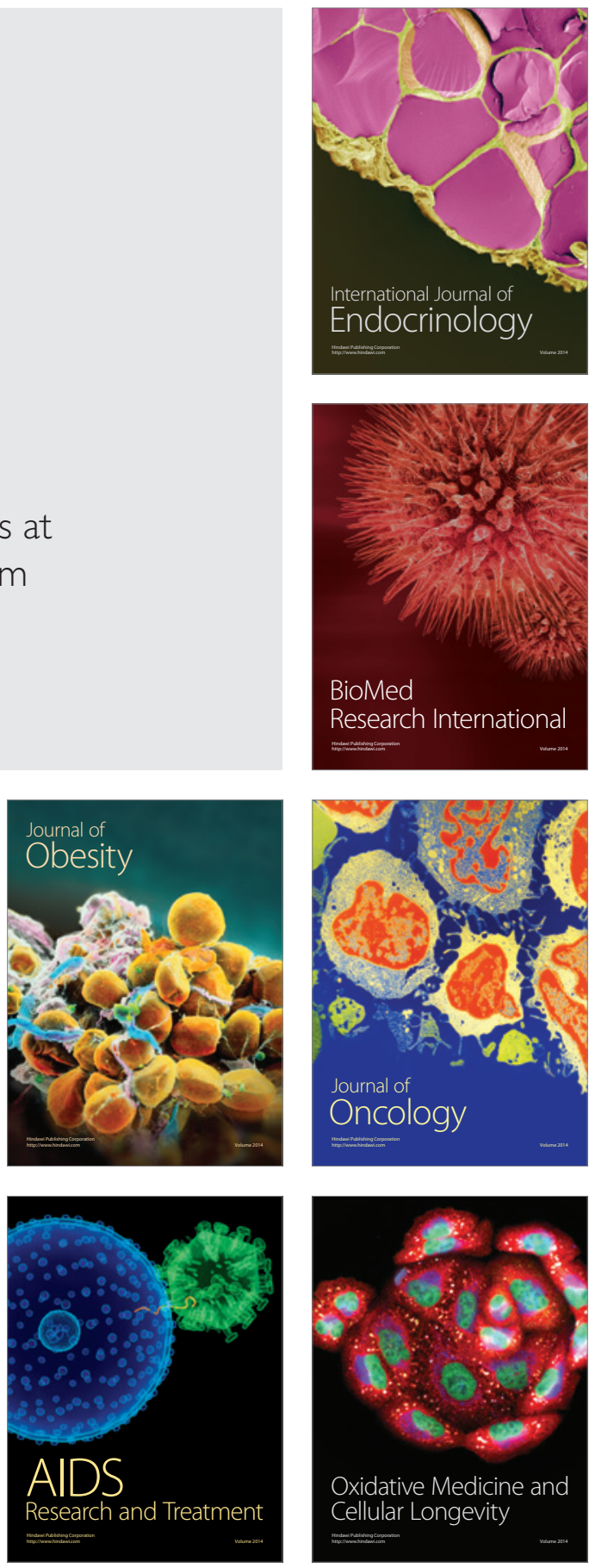